\title{
Coping e racionalização: Atuação de advogados nos casos de disputa de guarda
}

\author{
Josimar Antônio de Alcântara Mendes \\ Julia Sursis Nobre Ferro Bucher-Maluschke
}

\section{RESUMO}

Divórcio e sua judicialização expõem os advogados a vários fatores estressores inerentes ao contexto de crise, separação e disputa de guarda dos filhos. Este estudo discutiu a racionalização como coping de advogados para fatores estressores associados à atuação deles junto ao divórcio e à disputa de guarda na Justiça. $O$ delineamento do estudo foi qualitativo, exploratório e descritivo. Foram realizadas entrevistas qualitativas semiestruturadas individuais com dois advogados particulares e um público, todos com mais de oito anos de atuação em Varas de Família do Distrito Federal e Territórios. Os resultados indicam que, em função do contexto estressor em que atuam, os advogados tendem a racionalizar o litígio familiar, compreendendo-o como expressão de amor e afeto dos pais para com os filhos, caracterizandose, assim, como estratégia de coping por parte destes atores. Contudo, também apresentavam sinais de Burnout. Constatou-se que isso ocorre em função do processo de formação político-epistemológica do Direito, o qual não dá lugar e nem legitima as emoções e sentimentos dos advogados em sua prática profissional.

Palavras-chave: burnout; traumatização secundária; coping; custódia da criança; advocacia; psicologia forense.

\section{ABSTRACT}

\section{Coping and rationalization: Lawyers' practice in custody dispute cases}

Divorce and its legalization can expose lawyers to various stressors among custody dispute case context. This study discussed rationalization as coping strategy of lawyers to deal with stressors associated to their work within divorce and custody dispute in Family Courts. This study had a qualitative, exploratory and descriptive design. Individual semi-structured qualitative interviews were conducted with three lawyers with more than eight years of experience within family courts in the Distrito Federal, Brazil. The results showed the stressor context in which lawyers operate lead them to rationalize the family's dispute as proof of love and affect, which can be characterized as a coping strategy. However, they still have Burnout signals. This is due to the education process of lawyers, which do not recognize or legitimate the lawyers' feelings among their professional practice.

Keywords: burnout syndrome; secondary traumatization; coping; custody of children; lawyers; forensic psychology.

A família, enquanto um sistema e organismo vivo, se desenvolve ao longo do tempo. Parte desse desenvolvimento se dá por meio de um processo marcado por etapas, designado como Ciclo Vital da Família (Mendes \& Bucher-Maluschke, no prelo). Este ciclo é um movimento natural do desenvolvimento das famílias, o qual contempla uma série de etapas esperadas. Apesar disso, a forma como cada família irá passar por essas etapas é única, com processos de estruturação e significação idiossincráticos à cada sistema familiar (Mendes, 2013). Carter e McGoldrick (2003) esclarecem ainda que cada uma dessas etapas representa um momento de crise para a família.

\section{Sobre os Autores}

J.A.A.M.

orcid.org/0000-0001-8230-1998

Universidade de Brasília (UnB) -

Brasília, DF

josimards@gmail.com

\section{J.S.N.F.B.}

orcid.org/0000-0002-9194-8993

Universidade Católica de

Brasília (UCB) - Brasília, DF

psibucher@gmail.com

\section{Direitos Autorais}

Este é um artigo de acesso aberto e pode ser reproduzido livremente, distribuído,

transmitido ou modificado, por qualquer pessoa desde que usado sem fins comerciais. 0 trabalho é disponibilizado sob a licença Creative Commons CCBY-NC. 
Também existem etapas não esperadas no ciclo de vida das famílias, mas que são igualmente pertencentes àquele ciclo e engendram significativas mudanças nas relações do sistema familiar como um todo, por exemplo, a etapa do divórcio (Carter \& McGoldrick, 2003; Mendes, Bucher-Maluschke, Vasconcelos, Souza \& Costa, 2016; Ribeiro, 2010). A judicialização do processo de separação e divórcio faz-se necessária quando o subsistema conjugal não dá conta de manejar a situação de crise que o divórcio representa e, por conseguinte, não consegue fazer as partilhas e definições necessárias para a reorganização familiar e o bem-estar dos fiIhos. A depender da dinâmica estabelecida pela família, a etapa do divórcio pode representar uma legalização da discórdia entre o casal. Isso pode intensificar a necessidade de reorganização da estrutura doméstica e da convivência entre pais e filhos - característica comum a todas as etapas do $\mathrm{Ci}$ clo Vital da Família.

Quando ocorre a separação, o par parental se separa conjugalmente, mas não parentalmente. Santos e Fonseca (2003) reconhecem que separar os papeis conjugais dos parentais tem se mostrado, nos casos de disputa de guarda, como a maior dificuldade dos ex-casais. Os ex-cônjuges parecem vivenciar os seus papeis enquanto pais e cônjuges na mesma dimensão, mesmo antes da situação de divórcio. Ser um bom pai ou uma boa mãe seria, então, também ser um bom esposo ou uma boa esposa. Assim, quando um dos cônjuges falha no papel de esposo ou de esposa, falha também no papel de pai ou de mãe. Isso ocorre porque o par parental estabelece uma dinâmica na qual um avalia a competência parental do outro a partir da competência conjugal apresentada no decorrer do casamento desfeito (Ribeiro, 2010). Além disso, as fronteiras filiais, parentais e conjugais ficam difusas, pois as interações familiares pós-divórcio se ocupam em evitar a elaboração do sofrimento e do luto, o que pode levar a família a um prejuízo no seu desenvolvimento (Juras \& Costa, 2011). Assim, ao não saber separar os contextos, papeis e funções daquelas duas dimensões, e não se preocupar com a situação dos filhos, esses pais passam a entrar em uma disputa de poder, com dinâmicas de violência contra o ex-cônjuge, e até mesmo os filhos, configurando o divórcio destrutivo.

0 divórcio destrutivo pode ser entendido como a situação na qual o ex-casal, após a dissolução da união, passa a apresentar um padrão interacional e comunicacional conflituoso (Glasserman, 1989; Mendes, 2013). Isso ocorre porque os excônjuges ainda não são capazes de superar emocionalmente o divórcio, o que mantém as brigas e os desentendimentos mesmo após a separação (Juras \& Costa, 2011). Por conta disso, esse tipo de divórcio pode envolver grandes disputas e expressões de violências (Costa, Penso, Legnani, \& Sudbrack, 2009), gerando uma instabilidade no sistema familiar e, fre- quentemente, prejuízos aos interesses dos filhos.

Em qualquer família, em função da singularidade e subjetividade da qualidade das relações que ali são estabelecidas, pode haver o surgimento de alianças e coalizões que podem representar apoio mútuo, cuidados específicos, afinidade, identificação e etc. No domínio das relações e dos sentidos e significados que elas geram, as pessoas podem se conectar e desconectar umas das outras, por meio do movimento dialógico das relações. No caso das famílias em situações de divórcio, a formação de alianças e coalizões é um fenômeno que pode acontecer tanto por essa qualidade das ligações humanas, quanto pela necessidade se colocar diante dos conflitos e da ansiedade, angústia e tensões que são geradas com o divórcio. Assim, a situação de divórcio destrutivo pode levar a família até ao sistema judiciário, na tentativa de triangular novos elementos redutores de tensão, angústia e ansiedade no sistema: os juízes, promotores e profissionais forenses (Costa et al., 2009; Juras \& Costa, 2011; Mendes et al., 2016).

Em relação aos filhos, Straube, Gonçalves e Centa (2003) apontam que há consequências para o desenvolvimento psicoafetivo das crianças e adolescentes que vivenciam a situação de divórcio. Sobre o impacto psicossocial do divórcio no desenvolvimento de crianças, Nunes-Costa, Lamela e Figueiredo (2009) referem que tal situação tem um alto potencial de impacto no rendimento escolar e interação interpessoal das crianças, bem como na vulnerabilidade à ocorrência de depressão, ansiedade, aumento de estresse e consequente baixa imunidade. Nesse cenário, não é raro testemunhar os melhores interesses da criança (que vão desde a sua nutrição até a preservação emocional e afetiva) serem severamente aviltados durante o processo de disputa de guarda.

É diante da complexidade de todo esse contexto que a Justiça vai atuar enquanto elemento mediador dos direitos e deveres que circundam o sistema familiar. Um dos primeiros atores jurídicos a ter contato com essas pessoas - os jurisdicionados - são os advogados públicos e/ou particulares. Além de acolherem a queixa e as demandas de seus clientes - e verificarem se há legitimidade jurídica ou não no pleito -, serão os advogados que irão defender os direitos e interesses de seus clientes ao longo de todo o processo jurídico, estando expostos a vários fatores de estresse físico e emocional que a situação de divórcio pode gerar.

Jaffe, Crooks, Dunford-Jackson e Town (2003) conduziram um estudo quantitativo com 105 juízes americanos (54.3\% homens, $45.7 \%$ mulheres) com idade média de 51 anos e 10 anos de experiência, pelo menos. Em relação às Varas de atuação, $81 \%$ já haviam trabalhado em Varas/Juizados Criminais, $54 \%$ em Varas/Juizados ligados à violência doméstica e família, 30\% declarou ter tido experiência em Va- 


\section{WIN INTERACÃO EM ET. PSICOLOGIA}

ras da Infância e Juventude. Os participantes preencheram um questionário auto-administrado para medir estresse, burnout e trauma secundário. Os resultados indicaram que $63 \%$ dos juízes apresentavam um ou mais sintomas de estresse e traumatização secundária.

Em outro estudo quantitativo, Kriti, Shekhar e Jayashree (2012) realizaram um estudo transversal com uma amostra randomizada de 120 advogados (76 homens e 44 mulheres) atuantes no Tribunal do Distrito de Sangli, Índia. Com inventários apropriados, os autores mensuraram o score de estresse mental dos participantes, chegando a conclusão de que $88 \%$ dos advogados experienciaram estresse na sua prática profissional, sendo que $52,8 \%$ dos advogados homens também apresentavam scores significativos para abuso de substâncias.

No Brasil, Costa e Ferreira (2014) conduziram um estudo quantitativo sobre estresse ocupacional com uma amostra por conveniência de 702 advogados (sendo 53\% deles homens) de todas as regiões do país. Entre os aspectos avaliados, as limitações de atuação e controle dos resultados de seu trabalho apresentaram alta significância $(p<0,001)$ como preditores de estresse ocupacional. Além disso, o estudo concluiu que demandas psicológicas associadas ao trabalho dos advogados podem afetar a saúde física e psicológica deles.

Essas pesquisas ilustram uma constatação importante: a atuação profissional dos advogados tem impacto significativo na saúde mental e física desses profissionais. É necessário destacar que, a depender da área de operação do Direito (Direito Criminal, de Família, Tributário e etc.), esse impacto poderá ser maior ou menor. Em alguns advogados, uma alta carga de estresses profissional, afetivo e emocional pode levar a traumatizações secundárias ou vicariante (TS) e à Síndrome de Burnout (SB).

Alguns pesquisadores (Brobst, 2014; Jenkins, 2013; Morgillo, 2015; Murray \& Royer, 2004; Silver, Portnoy \& Peters, 2004) apontam que a ocorrência de TS é bastante comum na prática dos operadores do Direito, independente da área de atuação. O TS pode ser definido como alterações cognitivas e emocionais que surgem a partir da relação com pessoas traumatizadas (Jenkins, 2013; Brobst, 2014). Na situação de disputa de guarda, há um arranjo que pode potencializar a ocorrência desse fenômeno nos advogados: o divórcio destrutivo.

Outro fenômeno comum a esse contexto é a Síndrome de Burnout (SB). Esta síndrome caracteriza-se por um esgotamento físico e psicológico em decorrência do estresse profissional contínuo e relaciona-se a práticas profissionais que necessitam de atenção direta, contínua e significativamente emocional (Montero-Marín \& García-Campayo, 2010; Corrêa,
2015). A SB possui três dimensões: (a) exaustão emocional - fadiga física e esgotamento emocional; (b) despersonalização - dinâmica relacional em que o profissional despersonaliza o seu cliente, reificando as relações profissionais; e (c) baixa realização profissional - autopercepção profissional negativa, sentimento de incompetência profissional (Carlotto, 2015).

Quanto à ocorrência de SB em advogados, Levin (2008) aponta vários estudos que evidenciam a ocorrência de Burnout em advogados. Outros estudos (Berger, 2000; Jackson, Turner, \& Brief, 1987; Jaffe et al., 2003; Tsai, Huang \& Chan, 2009) também evidenciam isso. Destaca-se o estudo comparativo realizado por Levin e Greisberg (2003) para investigar a ocorrência de TS e SB em advogados. Nesse estudo, os autores aplicaram inventários próprios para a mensuração de sintomas de TS em três grupos diferentes: (1) advogados; (2) profissionais de saúde mental e (3) assistentes sociais. Os resultados mostraram que, em comparação com os outros dois grupos de profissionais, os advogados apresentam mais sintomas de TS.

Considerando esses dados, é possível supor que os advogados, ao estabelecerem suas relações profissionais com seus clientes, possam estar vulneráveis à TS e à SB, por conta do contexto tortuoso em que se estabelecem essas relações. De todo modo, Brobst (2014) reflete que a ocorrência de TS e SB em advogados de família é um tema ainda pouco abordado pela produção acadêmica e que isso tem impacto direto na qualidade dos serviços de Justiça que são oferecidos aos jurisdicionados. Isso se deve, em parte, à preocupação do exercício positivo do Direito que pressupõe objetividade e distanciamento profissional (Jenkins, 2013; Mendes, 2013; Mendes \& Bucher-Maluschke, no prelo).

Para lidar com os fatores estressores que podem levar à TS e SB, os advogados podem lançar mão de estratégias de enfrentamento, ou coping (Jaffe et al., 2003). Moreno, Gil, Haddad e Vannuchi (2011) esclarecem que o coping configura-se como a conjunção de esforços cognitivos e comportamentais com 0 intento de controlar, resistir e diminuir estressores internos e externos. Os autores ainda apontam duas formas de coping: (a) focado na emoção - desencadeiam estratégias defensivas e busca de aspectos positivos em situações majoritariamente negativas para reduzir a magnitude emocional dos fatores estressores; e (b) focado no problema - tentativas de definição e entendimento da situação estressora vivenciada, buscando e escolhendo situações alternativas.

Racionalizar a disputa de guarda e suas implicações pode configurar-se como uma estratégia de coping dos advogados que atuam nos casos de disputa de guarda (Mendes, 2013). A racionalização é um mecanismo de defesa psíquico que 


\section{W'INTERACÃO EM PSICOLOGIA}

emerge diante do desequilíbrio resultante da impossibilidade em conciliar aquilo que se deseja (o anseio, o querer e/ou aspiração conscientes) e a realidade - social ou psíquica - que se apresenta. Para Almeida (1996), esse desequilíbrio pode surgir diante uma ameaça ou uma dinâmica dialética tão insuportável que o indivíduo elege, inconscientemente, entre várias possibilidades, aquela que melhor se adequa, a mais interessante e/ou a mais útil, de modo a justificar ações e reestabelecer o equilíbrio psíquico perdido. Esse mecanismo não significa uma escolha consciente de justificativas ou motivos, mas, sim, uma escolha inconsciente, a qual seleciona as justificativas aceitáveis ou que melhor se adequam à situação; as alternativas e possibilidade inaceitáveis, insuportáveis, são jogadas ao limbo do esquecimento (Almeida, 1996).

Todas essas reflexões evidenciam que as relações interpessoais entre advogados e clientes têm impacto significativo no bem-estar e na saúde mental destes profissionais, à medida que são permeadas por fatores estressores e causadores de alta tensão psicológica. Isso ocorre porque a relação entre advogado e cliente é intensa e o seu grau varia de acordo com o tipo de representação, como nos casos de disputa de guarda, os quais demandam uma grande atenção e envolvimento dos advogados (Silver, 1999). Nesse mote, este artigo pretende discutir as implicações da racionalização de advogados, como estratégia de coping para fatores estressores associados à atuação deles junto ao divórcio, e o seu impacto sobre as crianças e adolescentes objeto de disputa de guarda nas Varas de Família.

\section{MÉTODO}

Este estudo enquadra-se no delineamento qualitativo, tendo como base um desenho metodológico com características exploratórias e descritivas. Os participantes desta pesquisa foram 1 advogada pública e 2 advogados particulares (um homem e duas mulheres) com atuação há mais de oito anos nas Varas de Família do Distrito Federal e Territórios. Todos os participantes trabalharam em Brasília e/ou em Regiões Administrativas do Distrito Federal.

\section{INSTRUMENTO E COLETA}

Os instrumentos utilizados foram a técnica da foto-elicitação associada à entrevista qualitativa semiestruturada individual. A técnica da foto-elicitação foi desenvolvida pelo fotógrafo e pesquisador americano John Collier, na década de 1950. A referida técnica consiste basicamente na inserção de fotografias/imagens na entrevista de pesquisa para evocar - eliciar - comentários, memórias, representações e discussões no decorrer de uma entrevista semiestruturada (Harper, 2002; Parker, 2009). Haper (2002) defende a utiliza- ção dessa técnica como importante método para se obter informações mais complexas sobre o objeto que se pretende investigar, acessando a subjetividade do entrevistado.

Nesta pesquisa, as imagens do referido instrumento, escolhidas a priori pelos pesquisadores, representavam um continuum, uma sequência completiva e interligada de doze imagens. Essa sequência fazia referência às etapas do Ciclo Vital Familiar de uma família e o seu percurso até a Justiça. A proposta era de que o(a) participante expressasse as suas percepções e perspectivas, inspirando-se naquelas imagens, à medida que elas Ihes fossem apresentadas. Com base na sequência de imagens, o(a) participante foi estimulado a elaborar pensamentos, ideias, valores e sentimentos que tinha sobre a temática do divórcio, disputa de guarda e as famílias que atende. Assim, pretendia-se alcançar os elementos que constituíam o olhar, a intervenção e a interação desses atores jurídicos junto às famílias em situação de disputa de guarda. Ao participante, era perguntado o que ele via em cada foto mostrada, qual era a cena, quais eram os atores, o que estava acontecendo, quais poderiam ser os sentimentos daquelas pessoas, além de perguntas abertas, pontuais e completivas relativas ao processo de separação e disputa de guarda. Foram realizadas três entrevistas com um tempo de duração entre $1 \mathrm{~h} 30 \mathrm{~min}$ e 2 horas.

\section{ANÁLISE DE DADOS}

A análise foi feita por meio da perspectiva construtivo-interpretativa proposta por González Rey $(2005 ; 2011)$. O princípio da análise construtivo-interpretativa é composto por processos reflexivos que se integram e desintegram ao longo da produção teórica, transbordando os processos de indução e dedução e estando em constante movimento (González Rey, 2005; 2011). Esse percurso de construção de informações é descrito por envolver desde o estabelecimento dos indicadores até a elaboração das Zonas de Sentido.

0 processo de construção desses indicadores é considerado dialógico e hipotético, permitindo a construção das informações e a emersão dos núcleos do sentido. Esses núcleos de sentido não são construídos de forma rígida e não são realizados pelos pontos mais frequentes, mas, sim, pelo que mais significa para os sujeitos (González Rey, 2005; 2011). Esses núcleos contêm sentidos subjetivos, os quais ainda não podem ser representados em sua forma mais complexa enquanto configurações subjetivas.

\section{RESULTADOS E DISCUSSÃO}

Durante a apresentação dos resultados e discussão, os participantes serão referidos da seguinte forma: Advogados (Adg01 e Adg02) e Defensor Público (Dfs). 
A partir da fala dos participantes, é possível perceber a utilização do mecanismo de racionalização da disputa/conflito e suas consequências, conforme evidenciam as falas abaixo:

"Quando um pai e uma mãe estão disputando [a guarda], é um bom sinal de que a criança tem um laço afetivo tanto com o pai quanto com a mãe. Tanto o pai como a mãe querem participar... Eles querem ter a criança" (Adg01)

"Quando tem a disputa, dessa forma [litigante], na separação, é bom porque a criança se sente amada, cada um ama de um jeito, mas vai amar" (Adg02)

"Às vezes, o que eu falo quando os pais estão brigando muito e a criança vê é: Nossa, você é tão amada que seu pai e sua mãe te querem, os dois te querem, estão loucos por você, a gente vai resolver as coisas aqui, da melhor maneira possível" (Dfs)

Essas falas sugerem a utilização da racionalização com uma estratégia de coping focado na emoção, uma vez que, por meio da criação de uma razão, de um sentido, de uma explicação clara, lógica e de conotação positiva, os advogados tentam extrair algo bom da situação de disputa de guarda, diminuindo, assim, a magnitude emocional da situação. Sugarman (2014) reflete que, comumente, os advogados tendem a se recusar a tomar medidas as quais eles acreditam que possam afetar negativamente o bem-estar das crianças. Esta afirmação é importante para a constatação de que a racionalização não serve apenas como coping para os fatores estressores do litígio familiar, mas também para justificar a própria ação litigante do advogado que, em defesa do seu cliente, poderá sim aviltar os melhores interesses da criança. Por isso, eles fazem essa relação direta entre disputa, litígio e afetividade, como uma tentativa de diminuir o caráter, muitas vezes, aviltador da sua prática - já que ela é sempre parcial, em defesa do cliente, que não é a criança.

Faticamente, o que se percebe nos litígios familiares judicializados contradiz a lógica de alusão da disputa à expressão de amor à criança (Mendes, 2013). Nessa situação, o par parental está tão envolto, tão imbricado nas suas próprias questões e sofrimentos que sequer consegue perceber a criança e o seu sofrimento, o que, sistematicamente, irá aviltar o seu bem-estar biopsicossocial (Fiorelli \& Mangini, 2009; Mendes et al., 2016; Ribeiro, 2010; Santos \& Fonseca, 2003). Assim, nos casos de alta beligerância, a disputa não se constitui em favor da criança e dos seus interesses, mas, sim, em favor de questões de ordem afetiva, psíquica e emocional do ex-casal, mantendo, assim, a criança e os seus melhores interesses alijados do processo de disputa.

A defensora reconhece o lugar abjetado da criança e seus interesses na situação de disputa de guarda:

"Ela [a criança] é objeto de disputa. Ela é quase que nem um personagem do processo. Ela nem é parte no processo" (Dfs)

Como que alguém, que é mero objeto de uma disputa, apenas um personagem no processo, pode estar sendo amado e cuidado? Essa contradição indica a dificuldade latente desses profissionais em lidar com o sofrimento da criança e o seu não-lugar no processo judicial. Por isso, diante da angústia e da ansiedade dessas constatações, racionalizam a disputa, percebendo-a como forma de demonstrar interesse, afeto e amor pela criança.

Apesar de não ser parte no processo judicial e de algumas práticas não atenderem ao seu bem-estar, a criança é um dos membros da família que mais sofre com a situação da disputa. Em adição, conforme apontado por Mendes \& Bucher-Maluschke (no prelo), a disputa de guarda não tem relação direta com a preocupação direcionada aos interesses da criança e do seu bem-estar. Tal argumento reforça a ideia de que aludir afeto e amor à disputa é uma forma de racionar o litígio e os seus desdobramentos prejudiciais aos melhores interesses das crianças. Por outro lado, sabe-se que, para o profissional, reconhecer as necessidades e bem-estar dos fiIhos, mas ver-se limitado pela epistemologia, prática, instrumentos da sua área, do seu serviço, e/ou pela complexidade da situação familiar, pode levar à ansiedade, angústia, sofrimento e até adoecimento psíquico que são desdobramentos comuns nas situações TS e SB.

Brobst (2014) reflete que, quando os advogados sentem que os seus clientes são tratados injustamente pelo sistema e as dinâmicas que o compõem, eles podem, emocionalmente, tomar para si essa pressão e responsabilidade, o que leva ao aumento dos estressores relacionados à prática profissional deles. Desta forma, compreende-se que a percepção da reificação e, por conseguinte, aviltação do bem-estar biopsicossocial da criança/adolescente durante o processo de disputa de guarda possa se constituir como um contexto estressor para os advogados que, como coping para a TS e $\mathrm{SB}$, passam a racionalizar a disputa.

Todo advogado que atua nos casos de disputa de guarda tem memórias duradoras de resultados de litígios que podem ter feito um cliente já vulnerável ainda mais vulnerável, e isso irá influenciar, consequentemente, as ações desse advogado em casos futuros (Brobst, 2014). Assim, a exposição a estressores e eventos traumáticos, e o emprego de estratégias de coping vão se constituindo com um continuum cíclico das práticas de racionalização embasadas, inclusive, em experiências profissionais anteriores.

Em função disso, Jenkins (2013) aponta a necessidade 
de treinamento para estudantes de Direito aprenderem a manejar esses fatores estressores e, assim, prevenir a TS e SB. Em adição, Carraro e Penso (2012) reforçam que a prática jurídica pode levar ao adoecimento psíquico e que, por isso, o acompanhamento psicológico para os esses atores deveria ocorrer nos tribunais.

\section{A defensora reconhece isso ao afirmar:}

"Tem dez anos que eu estou aqui na Vara de Família. Então, às vezes, o que me fragilizava há dez anos atrás, não me fragiliza mais e eu não acho isso bom. Os operadores do Direito também precisam de acompanhamento psicológico" (Dfs)

Antes disso, em um momento anterior ao início da conversação gravada, a defensora queixava-se com os companheiros de trabalho sobre o seu estado de saúde e que o médico havia lhe aconselhado que procurasse um psiquiatra. Aqui é possível perceber a ocorrência de sinais que sugerem a ocorrência de SB como o esgotamento físico e psicológico em decorrência do estresse profissional contínuo. Isso ilustra a afirmação de Sugarman (2014) de que, a depender das estratégias de enfrentamento para os estressores, os advogados podem continuar a sofrer Burnout. Ou seja, mesmo sendo uma estratégia de coping dos estressores, a racionalização não é assertiva, à medida que não impede a instauração SB e nem preserva os melhores interesses da criança, já que nega as dimensões e implicações do conflito familiar, abjetando a criança.

As percepções dos advogados evidenciam que, para eles, lidar com o jogo jurídico que se instaura diante da disputa de guarda é algo bastante desafiador e que, por isso, pode levar ao sofrimento e adoecimento psíquico. Isso se deve ao fato de que a atuação junto ao Direito da Família, em particular nos casos de disputa de guarda, está permeada por um complexo conjunto de desafios para advogado, o qual tem que lidar com uma clientela envolta em também complexas questões emocionais e litigantes (Sugarman, 2014).

\section{CONSIDERAÇÕES FINAIS}

Este estudo pretendeu refletir sobre as implicações da racionalização de advogados, como estratégia de coping para fatores estressores associados à atuação deles junto ao divórcio, e o seu impacto sobre as crianças e adolescentes objeto de disputa de guarda nas Varas de Família. Constatou-se que os advogados público e particular se deparam com o sofrimento da família, que o expressa por meio da criação e manutenção de conflitos. Esses profissionais reconhecem essa realidade, percebem a criança envolta nisso e, por não darem conta da angústia e ansiedade que isso lhes gera, racionalizam o conflito/disputa em como estratégia de coping para a traumatização secundária e o Burnout.

É importante compreender que, desde uma perspectiva complexa e dialética, as ações e consequências da interação interpessoal jamais serão lineares e/ou unidirecional. Ou seja, por mais que os resultados aqui apresentados indiquem que as crianças e adolescentes sofrem com as estratégias de coping dos advogados, este sofrimento decorre de um processo de adoecimento que leva a essas estratégias. 0 sofrimento e os danos aqui são para ambos, fato ilustrado por discussões e falas dos entrevistados que indicaram o fracasso de tais estratégias as quais, a longo prazo, retroalimentam os sintomas de burnout e TS, gerando uma espiral de sofrimento relacional neste contexto complexo que é a disputa de guarda, e aumentando as fragilidades do elo mais frágil desse sistema: crianças e adolescentes. Neste sentido, o foco dado preocupou-se em realçar essa dinâmica e pôr luz sobre essas vulnerabilidades e fragilidades.

0 que se percebe é que a forma como o conflito familiar é estruturado no litígio judicial, bem como o jogo jurídico que se instaura, transforma a criança em um ser-abjeto, posta em uma posição de "apenas um personagem", não sendo parte em um processo que diz respeito à sua guarda (ou seja, ao seu bem-estar e melhores interesses). Essa realidade se desdobra no sofrimento psíquico dos profissionais forenses diante das amarrações profissionais que o Direito e suas práticas proporcionam, levando-os a construir formas de enfrentamento para esse sofrimento. Essas formas podem, superficialmente, dar conta da angústia e da ansiedade desses profissionais, mas são duplamente disfuncionais ao não darem continência para aqueles elementos mais profundos que contingenciam o sofrimento desses profissionais e, principalmente, ao não salvaguardarem a criança e os seus melhores interesses.

Os resultados e reflexões apresentados indicam que o trabalho junto às famílias que chegam à Vara de Família é bastante complexo e gera afetos que tocam a subjetividade dos profissionais que atendem essas famílias. No contexto da Justiça, o objeto das práticas profissionais é o ser humano e as suas demandas. Mas também é o ser humano que atua junto às pessoas que chegam à Justiça. Esse encontro ser-humano-com-ser-humano produz várias qualidades e potencialidades que podem tanto favorecer, quanto prejudicar o atendimento das famílias jurisdicionadas, conforme já discutido na sessão dos resultados, constituindo-se, talvez, como um dos grandes pilares do caráter complexo da atuação nesse contexto. Por isso, é importante reconhecer que as emoções e afetos estão presentes em todo o tipo de relação humana e não há como rechaçá-las. Pelo contrário, é preciso reconhecê-las, entendê-las e compreender como elas afetam a relação advogado-cliente e as implicações disso para a meIhor operação do Direito e preservação dos melhores interes- 


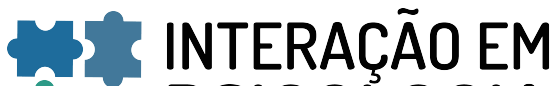 ET PSICOLOGIA}

ses da criança e também de sua família. Essa tarefa leva a dois problemas que asseveram ainda mais a situação: (1) a formação profissional dos advogados e (2) a falta de assistência psicológica para os atores jurídicos que atuam nos casos de disputa de guarda.

Em relação à formação profissional de advogados, o paradigma que guia a formação profissional dos operadores do Direito parece exigir deles alguns votos, tal como em um sacerdócio. 0 primeiro voto é o esvaziamento de sua subjetividade na prática jurídica. O segundo é a parcialidade a todo custo. A conjunção desses dois, leva a um último voto: a acriticidade - ou compreensões simplistas que pretendem reduzir a complexidade dos fenômenos e relações familiares. Assim, um primeiro passo para instrumentalizar os operadores do Direito com ferramentas de coping mais assertivas é repensar as concepções e práticas epistemológicas que embasam a formação e a prática desses profissionais, visando a construção de incursões epistemológicas que não só reconhecem a intersubjetividade entre advogados e clientes, mas que também tornem o olhar desses profissionais mais complexo e sistêmico diante dos fenômenos nos quais eles atuam.

A falta de apoio/suporte psicológico aos operadores do Direito, seja durante ou depois da sua formação, deveria ser revista. Não só porque isso contemplaria a integridade da saúde desses profissionais, mas também, e principalmente, porque essa ação teria impacto direto na promoção e legitimação dos melhores interesses da criança e da família, uma vez que os fatores estressores poderiam ser diminuídos e/ou melhor manejados, substituindo estratégias de coping menos assertivas como a racionalização.

As contribuições deste estudo restringem-se à prática dos advogados atuantes junto às Varas de Família, mais especificamente nas contendas de disputa de guarda. De todo modo, a literatura aponta que os fenômenos aqui descritos permeiam toda a prática dos operadores do Direito, independente da área de atuação. É necessário compreender os meandres das relações profissionais dos advogados com os seus clientes e as implicações disso para a saúde mental do sistema relacional advogado-cliente-família-justiça. Assim, este trabalho contribui para a ampliação da literatura sobre esse tema, o qual é praticamente escasso em Português e bem limitado na Língua Inglesa.

Em relação às limitações deste estudo, compreende-se que os resultados e reflexões aqui feitos baseiam-se no recorte possível a partir do número de participantes e local de atuação investigados. Estudos mais abrangentes e até quantitativos são desejáveis para ampliar a compreensão deste objeto no contexto brasileiro, o que é extremamente escasso até o momento, como já apontado.

\section{CONTRIBUIÇÃO DE CADA AUTOR}

J. A. A. M. e J. S. N. B. conceitualização; J. A. A. M. e J. S. N. B. investigação e visualização; J. S. N. B. supervisão; J. A. A. M. e J. S. N. B. redação - rascunho; J. A. A. M. e J. S. N. B. redação - revisão e edição.

\section{DECLARAÇÃO DE CONFLITOS DE INTERESSES}

Os autores declaram que não há conflitos de interesses no presente artigo.

\section{REFERÊNCIAS}

Almeida, W. C. (1996). Defesas do ego: Leitura didática de seus mecanismos. São Paulo: Ágora.

Berger, B. (2000). Prisoners of liberation: A psychoanalytic perspective on disenchantment and burnout among career women lawyers. Journal of Clinical Psychology, 5(56), 665-673. http://dx.doi.org/10.1002/(SICl)10974679(200005)56:5<665::AID-JCLP7>3.0.C0;2-J

Brobst, J. (2014). The impact of secondary traumatic stress among family attorneys working with trauma-exposed clients: Implications for practice and professional responsibility. Journal of Health \& Biomedical Law, 1(10), 1-51.

Carlotto, M. S. (2015). A relação profissional-paciente e a Síndrome de Burnout. Encontro: Revista de Psicologia, 12(17), 7-20.

Carraro, M. P. Q., \& Penso, M. A. (2012). Juízes de batina - reflexões sobre a relação entre a magistratura e o divino na formatação do arquétipo do juiz. Em M. A. Penso, \& T. M. C. Almeida (Orgs.), Direitos e conflitos psicossociais: Ações e interfaces disciplinares. São Paulo: Roca.

Carter, B., \& McGoldrick, M. (2003). The family life cycle. Nova York: Guilford Press.

Corrêa, J. S. (2015). Direito do trabalho e a saúde mental do trabalhador: considerações sobre a sindrome de burnout. Revista de Estudos Jurídicos, 2(25), 56-71.

Costa, M. F. A. A., \& Ferreira, M. C. (2014). Sources and reactions to stress in brazilian lawyers. Paidéia (Ribeirão Preto), 24(57), 49-56. http://dx.doi.org/10.1590/1982-43272457201407

Costa, L. F., Penso, M. A., Legnani, V. N., \& Sudbrack, M. F. O. (2009). As competências da psicologia jurídica na avaliação psicossocial de famílias em conflito. Psicologia \& Sociedade, 2(21), 233-241. http://dx.doi.org/10.1590/S0102-71822009000200010

Fiorelli, J. O., \& Mangini, R. C. R. (2009). Psicologia jurídica. São Paulo: Editora Atlas S.A. 
Glasserman, M. R. (1989). Clínica del divorcio destrutivo. Em J. M. Droeven (Org.), Mas allá de pactos y traiciones: Construyendo el dialogo terapéutico (pp. 251-303). Buenos Aires: Paidós.

González Rey, F. L. (2005). Pesquisa qualitativa e subjetividade: Os processos de construção da informação. São Paulo: Pioneira Thomson Learning.

González Rey, F. L. (2011). Pesquisa qualitativa em psicologia: Caminhos e desafios. São Paulo: Cengage Learning.

Harper, D. (2002). Talking about pictures: A case for photo elicitation. Visual Studies, 1(17), 13-26. http://dx.doi.org/10.1080/14725860220137345

Jackson, S. E., Turner, J. A., \& Brief, A. P. (1987). Correlates of burnout among public service lawyers. Journal of Organi-

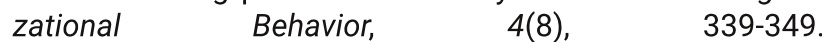
http://dx.doi.org/10.1002/job.4030080406

Jaffe, P. G., Crooks, C. V., Dunford-Jackson, B. L., \& Town, J. M. (2003). Vicarious trauma in judges: The personal challenge of dispensing justice. Juvenile and Family Court Journal, 4(54),

http://dx.doi.org/10.1111/j.1755-6988.2003.tb00083.x

Jenkins, M. L. (2013). Teaching law students: Lessening the potential effects of vicarious trauma. Manitoba Law Journal, 1(37), 398-418.

Juras, M. M., \& Costa, L. F. (2011). O divórcio destrutivo na perspectiva de filhos com menos de 12 anos. Estilos da Clínica; 1(16), 222-245. http://dx.doi.org/10.11606/issn.1981-1624.v16i1p222-245

Kriti, A. P., Shekhar, S. R., \& Jayashree, D. N. (2012). Occupational stress and burnouts as predictors of job satisfaction amongst lawyers in District Sangli. National Journal of Medical Research, 2(2), 141-144.

Levin, A. P., \& Greisberg, S. (2003). Vicarious trauma in attorneys. UMKC Law Review, 4(75), 965-998.

Levin, A. P. (2008). Secondary trauma and burnout in attorneys: Effects of work with clients who are victims of domestic violence and abuse. ABA Commission on Domestic Violence eNewsletter, 9 (Winter).

Mendes, J. A. A. (2013). Reflexões Sistêmicas Sobre o Olhar dos Atores Jurídicos que Atuam nos Casos de Disputa de Guarda Envolvendo Alienação Parental (Dissertação de Mestrado). Universidade de Brasília, Brasília.

Mendes, J. A. A. M., \& Bucher-Maluschke, J. S. N. F (no prelo). Destructive divorce in the Family Life Cycle and its implications: criticisms of Parental Alienation. Psicologia: Teoria e Pesquisa.

Mendes, J. A. A., Bucher-Maluschke, J. S. N. F, Vasconcelos, D. F., de Souza, G. G., \& Costa, P. V. M. N. (2016). Perspectiva Sistêmica: Um olhar necessário para atuação dos atores jurídicos junto à disputa de guarda. Nova Perspectiva Sistêmica, 25(54), 88-104.
Moreno, F. N., Gil, G. P., Haddad, M. D. C. L., \& Vannuchi, M. T. O. (2011). Estratégias e intervenções no enfrentamento da Síndrome de Burnout. Revista de Enfermagem UERJ, 1(19), 140-145.

Montero-Marín, J., \& García-Campayo, J. (2010). A newer and broader definition of burnout: Validation of the "Burnout Clinical Subtype Questionnaire (BCSQ-36)". BMC Public Health, 1(10), 302-310. http://dx.doi.org/10.1186/14712458-10-302

Morgillo, L. (2015). Do not make their trauma your trauma: Coping with burnout as a family law attorney. Family Court Review, $3(53)$, 456-473. http://dx.doi.org/10.1111/fcre.12167

Murray, D. C., \& Royer, J. M. (2004). Vicarious traumatization: The corrosive consequences of law practice for criminal justice and family law practitioners. Trabalho apresentado na Legal Profession Assistance Conference em Dalhousie University, Halifax, Nova Scotia, Canadá.

Nunes-Costa, R. A., Lamela, D. J. P. V., \& Figueiredo, B. F. (2009). Adaptação psicossocial e saúde física em crianças de pais separados. Jornal de Pediatria, 5(85), 385-396. http://dx.doi.org/10.1590/S0021-75572009000500004

Parker, L. D. (2009). Photo-elicitation: An ethno-historical accounting and management research prospect. Accounting, Auditing \& Accountability Journal, 7(22), 1111-1129. http://dx.doi.org/10.1108/09513570910987439

Ribeiro, R. (2010). A criança e o adolescente nos estudos psicossociais de varas de família. Em I. Ghesti-Galvão, \& E. C. B. Roque (Comp.), Aplicação da Lei em Uma Perspectiva Interprofissional: Direito, Psicologia, Psiquiatria, Serviço Social e Ciências Sociais na Prática Jurisdicional. Brasília, DF: Lumen Juris.

Santos, D. C. S., \& Fonseca, M. A. M. (2003). A regulamentação de visitas e a dificuldade de separação dos casais. Em H. G. D. Lima (Org.), Construindo Caminhos para a Intervenção Psicossocial no Contexto da Justiça. Brasília, DF: Tribunal de Justiça do Distrito Federal e dos Territórios.

Silver, M. A. (1999). Love, hate, and other emotional interference in the lawyer/client relationship. Clinical Law Review, 259(6), 261-313.

Silver, M. A., Portnoy, S., \& Peters, J. K. (2004). Stress, burnout, vicarious trauma, and other emotional realities in the lawyer/client relationship. Touro Law Review, 1(19), 847873.

Straube, K. M., Gonçalves, M. P., \& Centa, M. L. (2003). Percepção dos filhos sobre o divórcio dos pais. Família, Saúde e Desenvolvimento, 5(3), 173-184. http://dx.doi.org/10.5380/fsd.v5i3.8081 


\section{W'INTERACÃO EM \\ ET. PSICOLOGIA}

Sugarman, P. W. (2014). Navigating Emotional Challenges in the Legal Practice of Family Law: A Study of Burnout, Emotional Coping Strategies, and Competencies Using Grounded Theory (Tese de Doutorado). Alliant International University, San Diego.
Tsai, F. J., Huang, W. L., \& Chan, C. C. (2009). Occupational stress and burnout of lawyers. Journal of Occupational Health, $5(51)$, 443-450. 